\title{
Avaliação de materiais didáticos: uma proposta de ensino do conteúdo geometria molecular para alunos com deficiência visual
}

\author{
Evaluation of didactic materials: a proposal of teaching the molecular \\ geometry content for students with visual impairment
}

\author{
Ana Patrícia Martins Barros - E-mail: anapatriciamb@hotmail.com \\ Universidade Estadual da Paraíba - UEPB; Grupo de Pesquisa em metodologias para educação em \\ Química-GPMEQ \\ Francisco Ferreira Dantas Filho E-mail: dantasquimica@yahoo.com.br \\ Universidade Estadual da Paraíba - UEPB; Grupo de Pesquisa em metodologias para educação \\ em Química -GPMEQ.
}

Resumo: A pesquisa apresenta contribuições de um deficiente visual responsável pelo Departamento de Educação Inclusiva, quanto às potencialidades de uma proposta didática e os materiais nela utilizados, para o desenvolvimento da compreensão do conteúdo Geometria molecular em uma sala de aula inclusiva. Qualitativamente, este estudo possibilitou validar tais instrumentos observando o contexto da investigação e suas implicações ao propor esta averiguação. Do ponto de vista teórico nos pautamos em Manzato e Santos (2018), Gil (2002), Marconi e Lakatos (2003), Manzato e Santos (2016). A pesquisa exploratória aponta validar instrumentos e proporcionar familiaridade com o campo de estudo. Compõe a primeira etapa de um estudo mais amplo, e é comumente utilizada em pesquisas cujo tema foi pouco explorado, podendo ser aplicada em estudos iniciais para se obter uma visão geral acerca de determinados fatos. Os resultados são animadores tendo em vista que se trata de uma iniciativa para um maior diálogo e percepção para um campo epistemológico, visando uma construção significativa de uma educação inclusiva, principalmente em uma área ainda tão carente de materiais que possibilite essa inclusão, que é o ensino de Química.

Palavras-chave: Avaliação de uma proposta; Educação Inclusiva; Ensino de Química; materiais alternativos.

Abstract: The research presents contributions of a deficient visual responsible for the Department of Inclusive Education, as well as the potentialities of a didactic proposal and the materials used in it, for the development of the understanding of the content Molecular Geometry in an inclusive classroom. Qualitatively, this study made it possible to validate such instruments by observing the context of the investigation and its implications in proposing this inquiry. From the theoretical point of view, we are in Manzato and Santos (2018), Gil (2002), Marconi and Lakatos (2003), Manzato and Santos (2016). The exploratory research aims to validate instruments and provide familiarity with the field of study. It composes the first stage of a larger study, and is commonly used in research whose subject has been little explored and can be applied in initial studies to obtain an overview about certain facts. The results are encouraging 
given that this is an initiative for greater dialogue and perception for an epistemological field, aiming at a meaningful construction of an inclusive education, mainly in an area still so lacking in materials that makes possible this inclusion that is teaching of Chemistry.

Keywords: Evaluation of a proposal; Inclusive education; Chemistry teaching; materials.

\section{INTRODUÇÃO}

O ensino de Química para deficientes visuais é composto por linguagens e construção de métodos que procuram ser eficazes, tanto para indivíduos possuintes da deficiência quanto aos videntes, e tem por objetivo priorizar a formação do aluno como cidadão. Para que ele possa desenvolver habilidades e competências relacionadas à ciência, tecnologia e sociedade, a fim de articular o senso crítico sobre o espaço e o tempo e progredir o raciocínio lógico sobre o mundo.

A LDB (Lei de Diretrizes e Bases da Educação Nacional) instituiu a lei $n^{\circ}$ 9394/96, art. 58-60. Esta versa sobre o ingresso de alunos que possuem qualquer deficiência em uma sala regular em qualquer instituição de ensino. Em certa medida, a LDB veio atender à Conferência Mundial sobre Educação Especial, realizada no ano de 1994 em Salamanca-Espanha. Xavier (2016) destaca que o documento:

[...] trouxe novos objetivos para prover diretrizes básicas para a formulação e reforma de políticas e sistemas educacionais de acordo com o movimento de inclusão social. Este documento é considerado mundialmente um dos mais dentro do movimento de inclusão social, conforme o texto que discute a Declaração de Salamanca: promoveu uma plataforma que afirma o princípio e a discussão da prática de garantia da inclusão das crianças com necessidades educacionais especiais nestas iniciativas e a tomada de seus lugares de direito numa sociedade de aprendizagem (XAVIER, 2016, p.116).

Para Serra (2006), a inclusão escolar diz respeito ao direito à educação, comum a todos os cidadãos, e também o direito de receber a educação, sempre que possível, junto com as demais pessoas nas escolas regulares. Está defendida nos direitos humanos, na justiça social e na liberdade de escolha individual, baseada em interesses pessoais próprios de interação e relação com os grupos sociais distintos (RODRIGUES, 2006). São muitos os desafios da educação inclusiva, dentre eles, a singularidade de cada aluno e suas potencialidades. A educação inclusiva requer práticas mais cooperativas e o 
professor como agente efetuador do processo de inclusão escolar. As mudanças necessárias envolvem a revisão de metodologias, avaliações, projetos políticos pedagógicos, com adaptações curriculares que podem ser realizadas no âmbito do projeto pedagógico, do currículo desenvolvido em sala de aula e individual (BRASIL, 1999). Parte dessas estratégias requerem por sua vez, a formação do professor.

Vemos que o processo de ensino aprendizagem, que tem como público alvo os alunos com deficiência visual, vem se adaptando, juntamente com a legislação, para melhor afirmar esse direito. Dentro desse contexto, percebemos, no ensino de Química, uma carência significativa de um ponto essencial: os materiais didáticos adaptados para alunos com deficiência visual. Observamos o material didático como fundamental no processo de ensino e aprendizagem, tanto para professores, que o tem como um ponto de partida para o seu fazer pedagógico, como para os alunos, que o tem como um guia de estudos, uma maneira de relembrar conteúdos vistos ou de se programar para o que será estudado. Ao consultarmos a literatura da área, vimos que há estudos científicos que utilizam tais instrumentos como seus objetos de pesquisa (DIAS, CRISTOVÃO, 2009; DAMIANOVIC, 2007, entre outros), porém, para a realidade na qual vivemos, ainda são poucos. No que diz respeito à educação inclusiva, especificamente, compreendemos que o material didático escolhido para o ensino deve levar em consideração as particularidades, as necessidades, os ritmos e os métodos de aprendizagem do grupo em questão.

Pelo que observamos nos estudos e pesquisas referentes a essa discussão, percebemos que não há um grande número de materiais didáticos criados para alunos com deficiência visual, principalmente, no ensino das ciências naturais. E muitas das vezes, esses alunos, estão inseridos em salas de aula compostas, também, por alunos videntes, e nesse processo vemos a adaptação como uma maneira de assegurar seu direito à educação. Isto posto, para que alunos com deficiência visual tenham, verdadeiramente, acesso ao ensino de Química é necessário que os professores estejam conscientes de seus deveres enquanto educadores. Medrado (2014, p. 27) defende que "uma educação para todos é, sobretudo, um princípio que recomenda que o trabalho do professor não deve segregar, dificultar ou discriminar". Sendo assim, os professores devem estar preparados para receber seus alunos em sala de aula, fazendo adaptações de 
materiais, quando necessário, para que eles, também, possam participar ativamente do processo de aprendizagem.

Em nossa sociedade, criou-se uma premissa da relação do conceito do "ver" e "conhecer". Dessa forma, o ato de conhecer deve ser compreendido de acordo com as possibilidades e limitações do aprendiz, ou seja, de acordo com suas capacidades e limitações. Sobre isso, Pires (2005) afirma que "esse conceito de conhecimento é originado em uma sociedade formada, na sua maioria, por videntes" (PIRES, 2005, p. 18).

Um exemplo que pode ser trazido para nossa discussão é a utilização do termo "observação", bastante empregado no campo das ciências. Esse método de fazer ciência por meio da "observação", que implicitamente nós depreendemos que o investigador se utilizará, dentre outros meios, de sua visão, acaba por se tornar não-universal, visto que as pessoas com deficiência visual poderão compreender conceitos relativos à ciência por outros sentidos que não o da visão. Por isso, o sistema educacional, como um todo, deve desenvolver um ensino de qualidade e de forma variada que se adeque aos alunos, para que possa responder à inclusão e à eficácia devida. Os professores devem receber formação complementar que garanta em sua prática a possibilidade do ensino inclusivo. A reflexão deve expandir para além das responsabilidades do professor, sendo importante destacar que quando se trata de promover a inclusão, a infraestrutura das instituições de ensino também tem um importante impacto.

Estas devem contar com pisos com sinalizadores táteis em cada acesso que o aluno percorrer, além de elaboração e criatividade para pensar em propostas e materiais que consiga aproximar os alunos com deficiência visual o mais próximo possível da realidade concreta que os circundam, para que assim eles se sintam verdadeiramente incluídos nas salas de aulas. Para Santos et al. (2008), no tocante à diversidade, a escola é um espaço de intervenção didática. Portanto, aspectos relacionados à discriminação e ao desrespeito devem ser sanados, visando uma formação ética voltada para a diversidade e a igualdade de oportunidades. Vlado (2015) afirma com estas ideias, que a escola atua como um espaço de construção de saberes, onde a diversidade é inerente. Portanto, o processo formativo dos educandos deve estar voltado para uma formação 
ética, a qual desperte a importância do respeito e da valorização das diferenças, por meio da prática diária escolar e da reflexão continuada, para que assim se possa encarar a diversidade não mais como um obstáculo.

Segundo Schüetzer (2015), a educação inclusiva no Brasil começou a receber demanda para alunos com deficiência visual no século XIX. Porém, apenas a partir do século $\mathrm{XX}$, foi que a pedagogia começou a procurar meios diferentes para trabalhar com alunos com Necessidades Educacionais Especiais (NEE). A autora (op. cit., 2015, p. 49) conceitua inclusão como "o esforço para que as pessoas com deficiência convivam plenamente em todos os ambientes sociais" e esse esforço implica diretamente em acessibilidade.

Para Costa e Barros (2014, p. 82) “a imaginação e a curiosidade também constituem um diferencial no momento da aprendizagem científica", porém, para alunos videntes a imaginação e a curiosidade científica são, em boa parte, sanadas com imagens ou práticas para as representações biológicas dos conceitos que lhes são ensinados. Nepomuceno et al. (2016) diz que alunos com deficiência visual geralmente são desencorajados a participar de atividades envolvidas com as ciências, uma vez que precisariam sempre de suporte e supervisão, porque não conseguiriam executar as atividades comumente como os alunos videntes.

No que diz respeito às limitações que circundam o ensino de Química para alunos deficientes visuais, encontramos nas tecnologias assistivas uma alternativa para a reelaboração de conhecimentos e técnicas. A partir da utilização de equipamentos, mecanismos e reformulação de material didático acreditamos que ser possível neutralizar algumas barreiras originadas pela deficiência. Diante destes expostos, surgem os seguintes questionamentos: A utilização de materiais alternativos podem contribuir para a inclusão de alunos deficientes visuais em uma sala de aula inclusiva de forma que promova uma maior afetividade de toda a turma de forma mutua? Como uma proposta e a utilização de materiais alternativos podem contribuir para isso?

Assim, o presente estudo intenta contribuir com as demandas do processo de inclusão na educação básica, especialmente no contexto do ensino de Química, por meio 
da averiguação da potencialidade de uma proposta didática bem como do uso dos materiais nela utilizados.

Vaz et al. (2012) diz que quando os recursos didáticos são trabalhados em sala de aula pelo professor, é possível realizar a inclusão dos alunos com cegueira ou baixa visão, e isso é fundamental para que estes alunos aprendam e se aproximem de conceitos que antes, eram apenas ideias inteiramente abstratas em suas imaginações. $\mathrm{O}$ bom uso desses materiais pode favorecer, também, alunos que são videntes e fazer com que a aula para estes, torne-se mais dinâmica, atraente e contextualizada. Um fator importante para o sucesso de uma verdadeira inclusão é a instituição ouvir e atender à necessidade do professor e do aluno, para ambos trabalharem com os materiais necessários para facilitar o processo de ensino-aprendizagem, ajudando no rendimento do aluno, bem como, despertando a criatividade por meio do incentivo aos professores em tornar suas aulas inclusivas, contemplando assim a diversidade de uma sala de aula.

Acreditamos que a aprendizagem do conteúdo químico, assim como nas demais áreas do conhecimento, ocorre com a mediação do professor. Segundo Moraes (2003, p.197), a experimentação como atividade prática possibilita ao aluno "uma aproximação do trabalho científico e melhor compreensão dos processos de ação das Ciências". Observar, investigar o fenômeno, controlar variáveis, manipular equipamentos, registrar e sistematizar as informações são etapas fundamentais do experimento para que o aluno entenda o conteúdo estudado, isto é, os conhecimentos teóricos e práticos são complementares. Porém, quando se trata de alunos com deficiência visual as limitações são diversas. A possibilidade de participação de alunos com deficiência visual nestas atividades surge quando encontramos nas tecnologias assistivas alguma relação para tal aproximação. Por isso, a inclusão de alunos com deficiência visual na disciplina de Química tem dificuldade em relacionar a teoria estudada em sala de aula com a realidade a sua volta. E isso ocorre porque a teoria é constituída de conceitos que são abstrações da realidade (MACKINNON, 1999). Com caráter teórico e prático, a Química vê nas aulas experimentais um eficiente recurso didático para o ensino desse conhecimento. Todavia, ainda é a observação visual, o meio mais usado para coleta e interpretação dos dados, que dificulta a compreensão dos conteúdos previstos nos experimentos por deficientes visuais (BENITE et al., 2017). 


\section{METODOLOGIA}

A presente pesquisa é de natureza qualitativa no que se relaciona aos seus objetivos e configura-se como sendo exploratória (MOREIRA, CALEFFE, 2008).

Segundo Bortoni-Ricardo (2008), a pesquisa qualitativa objetiva desvendar o que está dentro do que ela chama de "caixa preta" do dia a dia das vivências escolares, sendo essa caixa os processos que, por serem realizados rotineiramente, deixam de ser notados e passam a ser executados de maneira automática pelos envolvidos. Em contrapartida, o professor, na condição de pesquisador, reflete sobre sua prática de modo a identificar possíveis problemas em sua ação e assim busca elaborar estratégias para sua melhoria.

Acerca do perfil de professor pesquisador, Bortoni-Ricardo (2008) afirma que o que distingue um professor pesquisador dos demais é o seu compromisso de refletir sobre a própria prática, buscando reforçar e desenvolver aspectos positivos e superar as próprias deficiências. Para isso, ele se mantém aberto a novas ideias e estratégias. Dessa maneira, identificamos a pesquisa desenvolvida como sendo qualitativa, visto que ela se propõe a averiguar o processo de aplicação de materiais alternativos, essenciais à prática pedagógica para um determinado conteúdo. Tal atividade, por ser praticada rotineiramente, pode se tornar pequena para os professores em meio as suas demais atribuições. Entretanto, essa tarefa tem papel fundamental, pois atua como um instrumento facilitador da aprendizagem no contexto mencionado.

Quanto à pesquisa exploratória, ela se desenvolve de modo a ambientar determinado problema de forma a evidenciá-lo para assim formular hipóteses e pressupostos a seu respeito. Esse tipo de pesquisa utiliza alguns dos seguintes instrumentos investigativos: 1) Entrevistas com pessoas que passaram por práticas ou problemas semelhantes ao estudado; 2) Levantamento bibliográfico; 3) Análise de exemplos para elucidar o problema em questão (SELLTIZ et al., 1967, apud GIL, 2002). Levando em consideração a aplicação da pesquisa exploratória e o presente trabalho, consideramos esta investigação com tais características, uma vez que ela se utiliza de situações cotidianas da prática pedagógica e propõe a reflexão a respeito dessas situações.

Para a realização deste trabalho foram percorridos os seguintes passos: 
- Observações em um centro de atendimento de crianças com deficiência visual;

- Elaboração de uma proposta didática para o conteúdo geometria molecular (conteúdo até então não trabalhado, devido sua complexibilidade);

- Produção de materiais que pudessem contribuir para a compreensão do conteúdo durante a aplicação da proposta;

- Averiguação da proposta bem como dos materiais, por um deficiente visual responsável pelo departamento de educação inclusiva da UEPB.

\subsection{PERFIL DO ENTREVISTADO}

Sobre o entrevistado, trata-se em um funcionário com cegueira congênita. Ele é responsável pela Secretaria e o Departamento de Educação Inclusiva da UEPB. Pensamos em sua contribuição na averiguação da proposta bem como dos materiais, uma vez acreditarmos em sua experiência cotidiana na elaboração de materiais para trabalhos voltados para educação de alunos com deficiência visual. Porém, em se tratando de um conteúdo considerado abstrato até mesmo para alunos videntes, sentimos a necessidade de suas contribuições, objetivando as possíveis limitações que poderiam surgir quando ela fosse aplicada com alunos com deficiência visual e que estavam matriculados em uma sala de aula inclusiva na rede regular de ensino.

\subsection{MATERIAIS ALTERNATIVOS}

Para Camargo (2008, p. 75), “enquanto a legislação brasileira prioriza a inclusão, na rede regular de ensino de alunos com algum grau de deficiência, os professores se sentem despreparados para recebê-los e atendê-los de modo adequado". Este autor evidencia que os professores reconhecem que um atendimento mais adequado seria função de docentes preparados, especificamente, para a educação especial. Da mesma forma, Cerqueira e Ferreira (1996) afirmam que, em nenhuma outra forma de educação, a adequação de recursos didáticos, onde as atividades experimentais se incluem fortemente, assumem tanta importância como na Educação Especial de pessoas com deficiência visual, levando-se em conta que:

[...] um dos problemas básicos do deficiente visual, em especial o cego, é a dificuldade de contato com o ambiente físico; a carência de material adequado pode conduzir a aprendizagem da criança deficiente visual a um 
mero verbalismo, desvinculado da realidade; a formação de conceitos depende do íntimo contato da criança com as coisas do mundo; tal como a criança de visão normal, a deficiente visual necessita de motivação para a aprendizagem; alguns recursos podem suprir lacunas na aquisição de informações pela criança deficiente visual; o manuseio de diferentes materiais possibilita o treinamento da percepção tátil, facilitando a discriminação de detalhes e suscitando a realização de movimentos delicados com os dedos (CERQUEIRA, FERREIRA, 1996, p.42).

A partir da observação a esses postulados teóricos e reconhecendo a necessidade de uma pesquisa nesse sentido, foi desenvolvida uma proposta de ensino para o conteúdo geometria molecular, no sentido de que tanto os alunos portadores de deficiência visual, quanto os videntes pudessem adquirir conhecimentos em conjunto, compartilhando dúvidas e aprendizagens, utilizando materiais de fácil manuseio.

\subsection{PROPOSTA DE ENSINO}

A proposta foi planejada para ser aplicada em uma sala de aula inclusiva, considerando o desenvolvimento da criticidade e apropriação do conhecimento por parte do aluno, tornado assim, os materiais alternativos indispensáveis ao processo de ensino e aprendizagem. Os materiais utilizados na abordagem do conteúdo desta proposta são materiais maleáveis e auto produtíveis dentro de qualquer realidade acadêmica, ou seja, é de fácil fabricação ou compra para professores em qualquer condição.

A escolha do material surgiu da necessidade de uma aproximação do conteúdo exposto em sala de aula, favorecendo uma maior acessibilidade dos alunos participantes com o real observado por alunos videntes. Cada material tem sua contribuição e particularidade, mas, a junção dos três materiais fez a diferença. Nesta proposta foram utilizados os seguintes materiais:

a) Sólidos Geométricos - Poliedros convexos regulares que permitem a visualização e manuseio dos tipos e números de faces, número de arestas e números de vértices (Figuras 1 e 2). Este material pedagógico proporciona uma compreensão tridimensional dos sólidos, tornando mais eficiente e didática o processo de ensino e aprendizagem no estudo da Geometria.

b) Geoespaço - O geoespaço é quadricular. Foi construído com madeira, ganchos e divisórias de acrílico removíveis (Figuras 3 e 4). Na Química, permite a 
construção de diversas formas moleculares com o auxílio de ligas de elástico. Este material facilitará o contato de alunos com deficiência visual na compreensão das estruturas de forma concreta e pode ser utilizado em grupo ou individual.

c) KIT Atomic Orbit Molecular de Química - Permite o manuseio e visualização tridimensional do mundo microscópico em nível atômico, tornando-se forte aliado no processo ensino-aprendizado da Geometria Molecular, Polaridade, Isomeria Espacial entre outros. Os átomos são feitos de núcleos de plástico com peças de ligação fixadas no ângulo correto. Além desse kit foi utilizado o Molymod - Um material em polímero, sendo seu formato mais arredondado e em maior diversidade na construção de moléculas de fácil manuseio e de grande utilidade no ensino de Química, que também contribuiu para compreensão da estrutura e montagem das geometrias. Na escolha desses materiais para esta proposta, acreditou-se que meios didáticos possibilitam que os estudantes interajam através de elementos concretos para formar novos conceitos, por meio de materiais portáteis de baixo custo e fácil construção, pois a "inclusão só ocorrerá quando o sujeito for aceito pelo ambiente de ensino, que deve oferecer as condições necessárias para que o processo de ensino e aprendizagem aconteça" (CAMARGO; NARDI, 2007, p. 379). Esses materiais proporcionam relacionar questões simples do cotidiano do estudante, sendo muitas vezes despercebidas pelos professores. No entanto, é preciso integrar cada vez mais teoria e prática, pois, conforme Rostirola e Schneider (2010, p. 76) "se faz necessário romper a distância entre o pensar e o fazer, entre a criação e a execução, entre a teoria e a prática".

No intuito de contribuir ainda mais para o desenvolvimento desta proposta, foi elaborada uma Apostila Complementar, baseada em recortes de livros, utilizados na Educação Básica para alunos videntes, e como o ensino para o deficiente visual privilegia a aquisição de conhecimento pela linguagem. É necessário o uso de livros didáticos e outros textos transcritos em Braille.

\subsection{INSTRUMENTOS PARA COLETA DE DADOS}

Os instrumentos utilizados para o desenvolvimento desta pesquisa foram: observação, questionário e entrevista. 
Quanto à observação, temos que ela é uma das técnicas mais utilizadas para obtenção de informações para pesquisas. Com este instrumento pode-se observar os fatos e correlações existentes. A observação, segundo Marconi e Lakatos (2003), é importante, pois pode comprovar uma teoria, um discurso na prática. O pesquisador precisa estar atento às situações ao seu redor, procurando compreender as condições objetivas e subjetivas que compõem o campo de estudo.

Já o questionário, é um instrumento constituído por uma série ordenada de perguntas que devem ser respondidas por escrito e sem a presença do entrevistador. Deve apresentar uma organização na obtenção de informações para facilitar a análise e tabulação das repostas. As perguntas devem ser claras e objetivas para evitar erros de interpretação, contudo, não devem ser indutivas.

Segundo Manzato e Santos (2018), as questões podem ser abertas, quando o entrevistado pensa sobre seu ponto de vista, e fechadas ou objetivas quando há opções de respostas. O questionário, segundo Gil (1999, p.128), pode ser definido "como a técnica de investigação composta por um número mais ou menos elevado de questões apresentadas por escrito às pessoas, tendo por objetivo o conhecimento de opiniões, crenças, sentimentos, interesses, expectativas, situações vivenciadas etc.”

A entrevista propicia situações de contato com o entrevistado, mesmo que seja necessário criar um ambiente informal para realizá-la. Trata-se de uma técnica rigorosa que necessita de um planejamento prévio e roteiros que delimitem o percurso para se alcançar os objetivos da pesquisa. Assim como o questionário, a análise das respostas de uma entrevista exige cuidado com as inferências, com a interpretação para se analisar fidedignamente a opinião do entrevistado (DUARTE, 2004).

Para Netto e Braz (2012, p. 22) “[...] o método de pesquisa que propicia o conhecimento teórico, partindo da aparência, visa alcançar a essência do objeto”. E, como já apontado, nossa pesquisa que é de cunho qualitativo buscou nos instrumentos capturar não só o que está posto, mas o reprimido no discurso, nas entrelinhas de cada resposta. Neste sentido, a entrevista possibilitou uma gama de informações essenciais para a reflexão crítica da proposta de aplicada. 


\section{APLICAÇÃO DA PROPOSTA A UM FUNCIONÁRIO COM DEFICIÊNCIA VISUAL - RESPONSÁVEL PELO DEPARTAMENTO DE EDUCAÇÃO INCLUSIVA}

Com a elaboração de uma proposta como ponto inicial, esta pesquisa buscou contribuir para melhor compreensão do conteúdo Geometria Molecular, no sentido de favorecer aos alunos com deficiência visual familiaridade com o conteúdo utilizando materiais alternativos, manipuláveis de fácil fabricação e adaptações. Percebemos a necessidade de validar esta proposta numa realidade mais próxima ao dos alunos cegos matriculados na rede regular de ensino.

Na aplicação desta etapa, recorremos, então, ao Técnico Administrativo do setor de Educação Inclusiva da Universidade Estadual da Paraíba, que é deficiente visual. Nós o procuramos, a fim de que o mesmo pudesse avaliar a proposta com ênfase na eficácia dos modelos geométricos no aprendizado de Geometria Molecular e/ou se eram necessárias algumas adaptações, em relação a tamanho e a outros aspectos físicos para a construção do modelo proposto. Solicitou-se que ele manipulasse o modelo Geoespaço, os sólidos geométricos e o modelo de molecular de polímero para reconhecimento. Explicamos que os mesmos representam núcleos de átomos e que estes, estariam ligados a outros núcleos, através de ligações, as quais apresentamos. Durante a aplicação foi indagado ao funcionário: É possível a percepção de formas geométricas nos diferentes materiais utilizados? O participante julgou o Geoespaço e os Sólidos Geométricos, mais facilitadores no reconhecimento das formas geométricas. Ainda destacou que em conjunto (Sólidos com o Geoespaço) ficaria mais fácil a reprodução das formas, uma vez que o ponto de norteio para a montagem de algumas estruturas eram os vértices dos sólidos, que, quando reproduzidas, eram substituídas por "ligas" (Figuras 1 e 2).
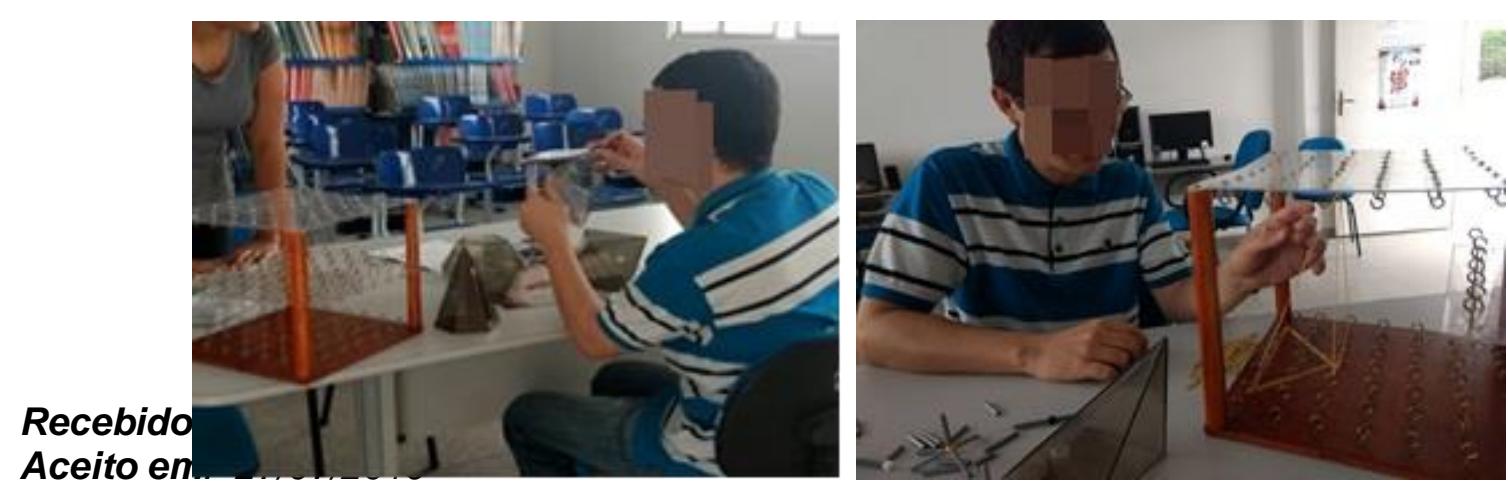
Figuras 1 e 2 - Manuseio dos materiais e montagem de algumas moléculas a partir da exposição da proposta

Fonte: Arquivo pessoal (2018).

Nestas imagens é percebível o contato do entrevistado com os materiais Geoespaço e os Sólidos Geométricos. Com o manuseio dos materiais, surgiram algumas contribuições referente à sequência da aplicação dos mesmos, quando o pesquisador sugeriu uma ordem definida para o uso destes materiais no desenvolvimento de aprendizagem para o conteúdo Geometria Molecular. Na percepção desse pesquisador, a utilização do Geoespaço, quando relacionado a outros materiais, muito contribui para o entendimento do estudo em questão.

Em seguida, o pesquisador avaliou os Kits Moleculares de Química, (Figuras 3 e 4), ressaltando que esses materiais são mais fáceis de manusear e perceber os elementos presentes na formação de uma molécula.
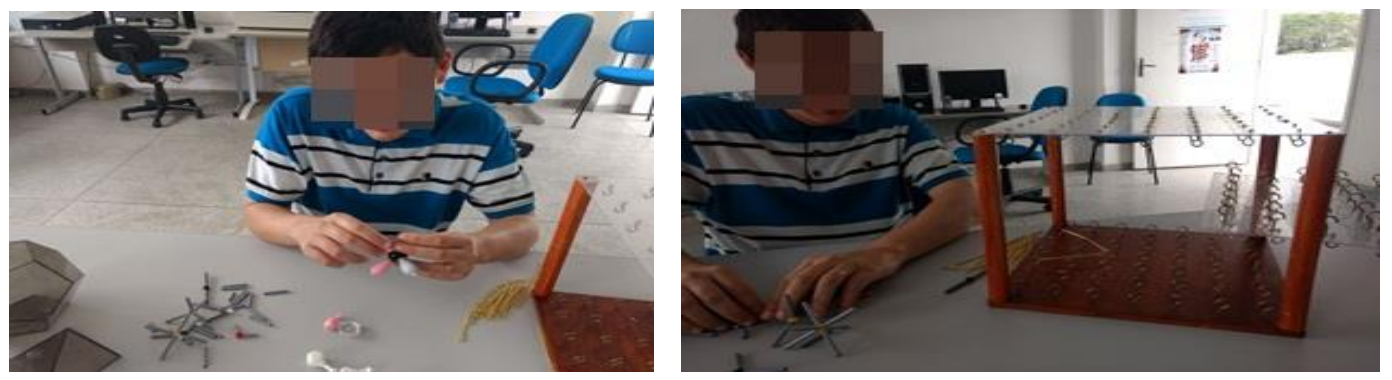

Figuras 3 e 4 - Manuseando os Kits Moleculares de Química e o Geoespaço.

Fonte: Arquivo pessoal (2018).

Durante o manuseio deste material, surgiu a seguinte dúvida: caso os professores queiram utilizar este conjunto de materiais no desenvolvimento deste conteúdo em sala, e que devido aos custos não pudessem ter acesso, o que poderá ser feito? Assim, como o Geoespaço, os Sólidos foram desenvolvidos artesanalmente, os Kits Moleculares podem ser substituídos por outras espécies, tais como: bolinhas de modelas e canudos, bexigas de assopro, materiais de isopor e arame, entre outros, que, aliás, já foram utilizados em atividades para diversos conteúdos com alunos cegos observados em outras pesquisas. Antes da Apostila ser confeccionada, o Técnico realizou uma pré- 
leitura da mesma e contribuiu na estruturação de alguns dados, a exemplo, a escrita e inserção de Figuras e Tabelas.

Finalizando, optou-se pela aplicação de um questionário com o objetivo de obter algumas percepções do funcionário, acerca da estrutura da proposta e dos materiais utilizados. Na primeira, questão indagou-se: Os materiais utilizados para o ensino de Geometria Molecular podem favorecer a compreensão do assunto e por quê? "Sim, o material produzido na sua pesquisa contribui para o desenvolvimento do aprendizado dos alunos, sobretudo, aqueles com deficiência visual. Pois, a disciplina de Química, nos diversos conteúdos trabalhados em sala de aula, a exemplo da Geometria molecular, é extremamente complexa para todos os alunos. Porém, para aqueles que possuem alguma deficiência visual, ela se torna ainda mais difícil o entendimento destes por ser uma disciplina que exige um estudo muito visual”.

Conforme opinião do entrevistado, o ensino de Química é considerado uma disciplina bastante complexa, bem como o conteúdo abordado. No entanto, a utilização destes materiais pode, sim, favorecer a compreensão, através de esclarecimentos dos conceitos que, até então, mesmo para alunos videntes, eram abstratos. Ainda sobre a questão, o participante foi convidado a relatar: De que forma, o uso dessas estruturas colaborativas poderia auxiliar e motivar a aprendizagem dos alunos frente aos conceitos de geometria molecular? E como, ele poderia classificar o desenvolvimento estrutural da proposta, visando sua aplicação em uma sala de aula mista na rede pública de ensino? E o respondente comentou: “A Química, muitas vezes, por ser uma disciplina abstrata, esses materiais pedagógicos auxilia o aprendizado do público-alvo, tornando conteúdos mais concretos. Excelente”.

Mediante as palavras do entrevistado, é perceptível quanto a disciplina de Química é algo complicado, e o quanto, em sua compreensão, os materiais expostos podem contribuir para o aprendizado. $\mathrm{O}$ participante ainda deixa claro a excelência da proposta em concordância com os materiais utilizados.

Na segunda questão, indagou-se qual era sua opinião acerca da utilização dos materiais e se estes estavam coerentes com a estrutura e o objetivo da proposta. A resposta foi promissora: "Acredito que há sim, porque se não houver o auxílio desse 
material fica muito complexo para os alunos cegos compreender o referido conteúdo”. Com isto, percebemos que a utilização de materiais, principalmente em turmas as quais se fazem presentes alunos com deficiência visual, é de extrema contribuição. E que sem estes o ensino na disciplina de Química, bem como seus objetivos pretendidos podem não ser alcançados Diante disso, é preciso que o educador perceba a necessidade de inovar em metodologias as quais os alunos com possam ser incluídos.

A terceira questão indagou ao entrevistado se o uso de materiais concretos maleáveis e uma Apostila auxiliadora poderiam contribuir (ou não) para essa realidade? O respondente comentou o seguinte: "É necessário, pois o emprego dessas ferramentas contribui para o desenvolvimento do aprendizado dos alunos cegos, tendo em vista a complexidade do conteúdo de Geometria Molecular”.

Analisando a opinião do respondente, percebe-se que o conjunto de materiais apresentados contribui para o desenvolvimento do conteúdo e que a utilização dos mesmos, nesta proposta, é necessária no que concerne à realidade em que se encontra as escolas de rede pública e privada. No que se refere aos alunos videntes, indagou-se ao Técnico: Você acha que este tipo de proposta pode expandir a inclusão e mudar a forma com que alunos videntes observam e tratam os colegas em uma sala de aula? E seu posicionamento foi: "Essa é uma proposta inclusiva porque o desenvolvimento dessas ferramentas pedagógicas torna os conteúdos mais acessíveis para os alunos com deficiência visual fora e dentro de sala de aula". Perfazendo uma análise da resposta do entrevistado, percebe-se a eficiência do material, destacando-se ainda que estes irão para além da sala de aula. O que nos torna esperançosos acerca da promoção de atitudes inclusivas, principalmente, no ensino de Química, bem como a eficiência desta proposta quando aplicada na Educação Básica.

Em relação ao conhecimento Químico, indagou-se ao funcionário se ele citaria alguma limitação que poderia surgir no desenvolvimento da aplicação desta proposta. E se caso a resposta fosse "sim", qual seria sua origem ou motivo? Ele respondeu: Até então, não observo nenhuma limitação ao manusear esse material. No entanto, as dificuldades poderão surgir de acordo com o desempenho de cada pessoa ao utilizálo”. Percebemos a partir desta colocação que, na compreensão do participante, não há 
limitações no manuseio do material e na estrutura para aplicação da proposta. Destacamos, porém, que existe a possibilidade de surgir entraves, mediante o desempenho de cada indivíduo. Isto nos alerta a observar de forma individual, e não coletiva, os alunos que venham utilizar esses materiais.

Em relação à qualidade dos materiais utilizados para o conteúdo desenvolvido nesta pesquisa, questionou-se o seguinte: Qual a sua opinião em relação ao tamanho, qualidade, facilidade de manuseio do recurso didático para aprendizagem? Assim respondeu o entrevistado: "Não vejo problema nesses materiais pedagógicos. Porém, a dificuldade que verifiquei foi com relação àquele que precisa de ligas para manuseá-lo. O entrevistado já havia colocado em questão o grau de dificuldade percebido no manuseio utilizando o Geoespaço, contudo, destacou sua contribuição quando relacionados aos demais materiais. Nesta questão, ele expôs, inclusive, a qualidade dos materiais até o momento quando da sua utilização.

Encerrando esta averiguação da proposta, solicitamos ao entrevistado que relatasse, de forma geral, os aspectos em relação aos seguintes pontos: Uso dos materiais em sala de aula; Se a utilização dos materiais demonstrativos auxilia na aprendizagem dos alunos frente aos conceitos científicos; Pontos positivos e negativos na utilização dos materiais e quais as sugestões para modificar os materiais de forma que venha facilitar o entendimento do conteúdo Geometria Molecular? Em resposta ele comentou: Observo que as construções desses instrumentos pedagógicos são importantes para o desenvolvimento do aprendizado de todos os alunos, sobretudo, para aqueles que possuem deficiência visual, bem como tornar o ambiente escolar inclusivo e acessível para todos que necessitam estudar. Verifico também, que os materiais disponibilizados estão acessíveis. Entretanto, no decorrer da pesquisa ou posterior a ela, poderão surgir propostas de alteração ou desenvolvimento de novos materiais, mas isso, dependerá da interação do público-alvo da pesquisa com os referidos instrumentos pedagógicos.

Evidenciou-se que o entrevistado fez o relato dos aspectos que, para ele, eram os que mereciam atenção e, como pode ser observado, relatou a importância do desenvolvimento de materiais para alunos com deficiência visual e ainda, na 
possibilidade de tornar o ambiente escolar verdadeiramente inclusivo, viabilizando acesso a todos que necessitam aprender. Ainda acerca dos materiais, destacou a acessibilidade dos mesmos. Entretanto, lançou a possibilidade de surgimentos de possíveis alterações, pontos negativos, críticas, na visão de outro público.

Partindo das contribuições apontadas pelo entrevistado, para uma maior reflexão a respeito da estrutura da proposta, bem como aplicação dos materiais, reorganizou-se todos os pontos, aplicou-se a proposta com um grupo de professores de Química de uma turma de Pós-Graduação de uma Instituição Pública. De igual modo, aplicou-se também com professores em formação do curso de Química, matriculados na disciplina Educação Inclusiva - componente obrigatório do curso.

\section{CONSIDERAÇÕES FINAIS}

Percebemos que foi de grande importância as contribuições do entrevistado, uma vez que os resultados desta pesquisa abrem um leque de oportunidades para pesquisas futuras no campo da inclusão de alunos deficientes visuais. Os modelos didáticos aqui apresentados podem ser utilizados para uma futura pesquisa de validação em salas de aulas do ensino básico ou do ensino superior, para observar se os mesmos possuem potencial de uso real em sala de aula. Concluímos que é indiscutível o papel do material didático como recurso incentivador da aprendizagem. Defendemos a importância do uso de materiais didáticos pautados em Vygotsky (1998), visto que o indivíduo aprende usando instrumentos e criando signos. Sendo assim, o conhecimento não acontece apenas com a presença de educadores. $\mathrm{Na}$ perspectiva da teoria sociocultural vygotskyana, o processo de ensino e aprendizagem é um trabalho global, não isolado, em que relações pautadas em colaborações ocorrem, não só entre professor e alunos, mas também entre os próprios alunos.

Nesse sentido, os materiais didáticos são ferramentas culturais utilizadas na mediação da aprendizagem por professores e alunos. E para contribuir Malheiros (2013) defende que o uso de materiais didáticos proporciona, no processo de ensino e aprendizagem, alguns benefícios como a facilidade para fixar a aprendizagem, simplicidade na apresentação de dados, possibilidade de tornar os conteúdos mais concretos e estímulo à participação dos alunos. Tais benefícios, com as contribuições do 
entrevistado, ficaram evidenciados. E isto nos leva a acreditar que, quando aplicada, a proposta e os materiais poderão ser de grande contribuição na compreensão do conteúdo objeto desta pesquisa.

Por fim, ainda cabe ressaltar que o processo de inclusão deve ser visto como uma necessidade para a sociedade, mas, para isso, a escola deve estar aberta e preparada para receber os alunos, adaptar-se e oferecer um ambiente favorável à aprendizagem. Pois, conforme percebemos, a aplicação e utilização de materiais alternativos podem possibilitar essa aprendizagem.

\section{REFERÊNCIAS}

BENITE, C.R.M.; BENITE, A.M.C.; BONOMO; F.A.F.; VARGAS, G.N.; ARAÚJO, R.J.S.; ALVES, D.R. Observação inclusiva: $O$ uso da tecnologia assistiva na experimentação no ensino de Química, v.12, n.2, p.94-103, 2017.

BORTONI-RICARDO, S. M. O professor pesquisador: introdução à pesquisa qualitativa. São Paulo: Parábola Editorial, 2008. p.41-58.

BRASIL, Conselho Nacional de Educação. Resolução CNE/CP n. 1, de 18 de fevereiro de 2002. Disponível em: http://portal.mec.gov.br/cne/arquivos/pdf/009.pdf. Acesso em dezembro de 2018.

CAMARGO, E. P. Ensino de Física e Deficiência Visual - Dez Anos de Investigações no Brasil. São Paulo: Plêiade, 2008. 205 p. CERQUEIRA, J. B.; FERREIRA, E. M. B. Os recursos didáticos na educação especial. Disponível em http://www.deficientesvisuais.org.br/Artigo17.htm. Acesso em maio de 2018.

CAMARGO, É. P.; NARDI, R. Planejamento de Atividades de Ensino de Física para alunos com deficiência visual: dificuldades e alternativas. Revista Electrónica de Enseñanza de las Ciencias, v. 6, n. 2, p. 378-401, 2007.

COSTA, E. C. P.; BARROS, M. D. M. de. Luz, câmera, ação: o uso de filmes como estratégia para o ensino de Ciências e Biologia. Revista Práxis, v. 6, n. 11, 2014.

DAMIANOVIC, M. C. Material didático: De um mapa de busca ao tesouro a um artefato de mediação. In: DAMIANOVIC, M. C. (Org.) Material Didático: Elaboração e Avaliação. Taubaté-SP: Cabral Editora e Livraria Universitária, 2007. p. 19-32.

DUARTE, R. Entrevistas em pesquisas qualitativas. Educar. Curitiba, n. 24, p. 213225, 2004. Editora UFPR. Disponível em: https://revistas.ufpr.br/educar/article/view/2216. Acesso em dezembro de 2018. 
GIL, A. C. Como elaborar projetos de pesquisa. Editora ATLAS. 4. Ed. São Paulo. 2002.

GIL, A. C. Métodos e técnicas de pesquisa social. 5. ed. São Paulo: Atlas, 1999. In: GIL, A. C. Como Elaborar Projetos de Pesquisa. 4. ed. São Paulo: Atlas, 2002.

MACKINNON, G. R. Students' Understanding of Orbitals: A Survey. ERIC_NO: ED433248 [S.I.], 1999.

MALHEIROS, B. T. Didática Geral. LTC. Rio de Janeiro - RJ. 2012.

MANZATO, A. J.; SANTOS, A. B. A elaboração de questionários na pesquisa qualitativa. Disponível em: http://paginapessoal.utfpr.edu.br/lilianvismara/es17emestatistica/a-elaboracao-de-questionarios-na-pesquisa. Acesso em dezembro de 2018.

MARCONI, M. A.; LAKATOS, E. M. Fundamentos de metodologia científica. 5. ed. São Paulo: Atlas 2003.

MEDRADO, B. P. Diálogos, ações e desafios: Os caminhos de um projeto de pesquisa. In: MEDRADO, B. P. (Orgs.). Deficiência Visual e Ensino de Línguas Estrangeiras: Políticas, Formação e Ações Inclusivas. Campinas, SP: Pontes Editores, 2014, p.27.

MORAES, R. (Org.). Construtivismo e ensino de ciências: reflexões epistemológicas e metodológicas. Porto Alegre: EDIPUCRS, 2003.

MOREIRA, H; CALEFFE, L. G. Metodologia da pesquisa para o professor pesquisador. 2. Ed. Rio de Janeiro: Lamparina, 2008.

NEPOMUCENO, G. M. et al. The value of safety and practicality: Recommendations for training disabled students in the sciences with a focus on blind and visually impaired students in chemistry laboratories. Journal of Chemical Health and Safety, v. 23, n. 1, p. 5-11, 2016.

NETTO, J. P.; BRAZ, M. Economia Política: uma introdução crítica. São Paulo: Cortez, 2012.

PIRES, E. O ensino de Física no contexto da deficiência visual: elaboração e condução de atividades de ensino de Física para alunos cegos e com baixa visão. Tese de doutorado. Campinas/SP, Unicamp, 2005. 285p.

ROSTIROLA, C. R.; SCHNEIDER, M. P. Projeto Politico Pedagógico: instrumento de melhoria da qualidade educativa? Joaçaba Unoesc e Ciência - ACHS, vol. 1, 2010.

RODRIGUES, D. Inclusão e educação: doze olhares sobre a educação inclusiva. São Paulo: Summus, 2006.

SANTOS, M. P.; PAULINO, M. M. Inclusão em Educação: Cultura, Políticas e Práticas. São Paulo, 2008. 
SERRA, S. Inclusão e ambiente escolar. In: SANTOS, M.P.; PAULINO, M.M (org.) Inclusão em educação: cultura políticas e práticas. 2. ed. São Paulo: Cortez, 2006.

SCHÜETZER, D. B. Uma face da confessionalidade: a inclusão de pessoas com necessidades educacionais especiais no ensino superior. Revista de Educação do Cogeime, v. 24, n. 46, p. 45-58, 2015.

VAZ, J. M. C. et al. Material didático para ensino de biologia: possibilidades de inclusão. Revista Brasileira de Pesquisa em Educação em Ciências, v. 12, n. 3, 2012. Disponível

em: 1https://www.researchgate.net/profile/Tereza_Orlando2/publication/273359243_Didact Di_Material_for_Biology_Education_Inclusion_Possibilities/links/54ff19c60cf2741b6 9f2e287.pdf. Acesso em novembro de 2018.

VYGOTSKY, L.S. A formação social da mente. 6. ed. São Paulo: Livraria Martins Fontes, 1998. Psicologia Pedagógica. São Paulo: Martins Fontes, 2001.

VLADO, Educação. Orientações Gerais: Educação em Direitos Humanos. 1. Ed. São Paulo: Instituto Vladimir Herzog, 2015.

XAVIER, A. V. O. A Inclusão da Pessoa com Deficiência na Escola Regular. Arcos. Disponível em: http://www.arcos.org.br/artigos/a-inclusao-da-pessoa-com-deficienciana-escola-regular/. Acesso em novembro de 2018. 